\title{
Sunscreen and moisturizer cream effects of cosmetic formulations containing extracts of Hypnea musciformis collected in the Colombian Caribbean
}

\begin{abstract}
Background: Three cosmetic products were developed: moisturizer, sunscreen and gel mask; their ingredients are innovative since they have extract of Hypnea musciformis a seaweed found on the coast of Colombia.

Objectives: To determine that cosmetic products do not cause skin irritation and that they can protect the skin from sunlight. To measure with organoleptic tests the smell, texture and color of the products. To perform microbiological and physical-chemical tests of these cosmetic products.
\end{abstract}

Methods: The active compounds present in H. musciformis were obtained with the supercritical extraction method. The cosmetic formulations were made with components approved by the European Standard No. 1223.UV filters, extracts of $H$. musciformis, Vitamins $\mathrm{A}, \mathrm{B}$ and $\mathrm{D}$, collagen and aloe vera were added. Evaluation: The photo protective effects were measured and in-vivo tests were carried out to determine if the formulations rise irritation.Physicochemical properties: density, viscosity and $\mathrm{pH}$ of all formulations were determined. Microbiological tests: the presence of Staphylococcus aureus, Pseudomonas aeruginosa and coliform bacteria was evaluated. Sensory tests: product approval was measured by color, odor and texture.

Results: The ultraviolet spectrum showed absorbances of $190 \mathrm{~nm}, 290 \mathrm{~nm}$ and $365 \mathrm{~nm}$ wavelengths. Relative densities were: mask: 1.0062 , moisturizer: 0.9337 , sunscreen 0.9802. pH: mask: 6.90, moisturizer: 6.86 and sunscreen: 6.82.The moisturizer and sunscreen viscosity shows a pseudoplastic behavior; the mask has a viscosity of $7.46 \times 10^{-4}$ $\mathrm{Pa}^{*} \mathrm{~s}$. There is no presence of Staphylococcus aureus, Pseudomonas aeruginosa or coliform bacteria. The skin irritation test in vivo showed $100 \%$ negative results. The cosmetic products do not irritate the skin. The results of the sensory evaluations show an approval in smell, color and texture.

Conclusions: H. musciformis extracts are considered effective ingredients to use in sunscreen and moisturizer formulations. The combination of vitamins A, B and D, aloe vera, collagen and alga extract significantly improves its properties.

Keywords: Hypnea musciformis, carrageenan, irritation test, sensory test, microbiological control

Abbreviations: H. musciformis, Hypnea musciformis; UV, ultraviolet radiation; CFU, colony forming unit; TSB, Triptych soy broth; BGLB, bright green lactose broth; nm, nanometers; SF, supercritical fluids; IDEAM: Meteorology and Environment National Institute; INVIMA: National Institute for Food and Medicine Regulating Supervisor

\section{Introduction}

In Colombia there are around 500 species of macroalgae. ${ }^{1}$ The Hypnea musciformis algae grows in Santa Martha and San Andrés on shallow rocks and it is exposed to surface waterAt some times of the year, there are red algae in Santa Marta and La Guajira. ${ }^{2}$ The great variety in species and the abundance of these organisms represent an availability of this natural resource. Since algae could be exploited for the benefit of human communities. The traditional knowledge from people, regarding the use of natural products, tends to have a scientific foundation still unknown to the communities. But it may be the basis for optimizing the use of this resource. ${ }^{3}$

This would also allow promoting the consumption of this product
Volume 8 Issue 3 - 2020

\author{
Paula Alejandra Vargas Aya, Gladys Rozo \\ Torres \\ Jorge Tadeo Lozano University, Colombia
}

Correspondence: Paula Alejandra Vargas Aya, Jorge Tadeo Lozano University, Research Line:Algae chemistry, Research group: bio-prospecting and biotechnology, Calle I34D \# 49-35, Bogotá DC, Colombia, Tel $(+57) 3186240353$, Email paulaa.vargasa@utadeo.edu.co

Received: May 19,2020 | Published: June 26, 2020 based on real and verifiable data. This could lead into a marketing strength. Possibly, it would yield higher profits for those Caribbean people who receive some income from the sale of these cosmetic products. $^{4}$

Algae have a very important role in the production of cosmetic products, since they help with hydration. They have this property thanks to their content of phycocolloids, which are the agar found in red algae. Some have alginic acid and carrageenans, compounds that are able to retain water. That is the reason why they are suggested as moisturizers. $^{5}$

Alga extract Hypnea musciformis has a positive effect on the skin, since it helps to repair and relieves injuries caused by UV rays or sunburn. ${ }^{6}$

Additionally, this alga produces K-carrageen an, a highquality polysaccharide. It also has substances that are used in the pharmaceutical industry for its antiviral, anti-inflammatory and muscle relaxant properties. ${ }^{7}$ Moisturizing creams are emulsions primarily designed to restore and regenerate the lipid barrier of epithelial cells as well as to maintain optimal epidermal hydration. ${ }^{8}$ 
The masks based on natural products have a great benefit on the skin. They provide hydration and nourishment as well as a natural and youthful appearance. ${ }^{9}$

Since Colombia is located in the equatorial zone, the solar rays fall through directly. Therefore, UV radiation becomes more intense in that area according to a study carried out by IDEAM and the Ecuadorian Civil Space Agency (EXA). ${ }^{10,11}$ For this reason, it is very important to use sunscreen to prevent skin diseases. Long-term exposure to ultraviolet (UV) radiation is a risk factor for most skin cancer disease. ${ }^{12}$

The conditions of the skin have a remarkable impact on the life of population and their health condition. Especially in those countries which do not have seasons like Colombia. In order to accomplish a more efficient and affordable medical treatment for skins which are exposed to the sun all year long. Thus, new therapeutic approaches have been under continuous research. These approaches are based on the use of algae, which have emerged as a therapeutic option with a lower cost in Latin America. ${ }^{13}$

Using algae is part of the human culture basis. In the last few years, the number of studies based on reporting the components and the antioxidant features of the secondary metabolite of this specie have increased. Even, in some cases have been considered as chemoprevention agents. ${ }^{14}$

During the last 10 years, our research team has been testing algae extracts from different contexts such as food and health. However, currently, our interest is in starting a new cosmetic line ${ }^{15}$ preferably based on studies about skin damage caused by the UV light exposure.

Yet, in Colombia the usage of algae is merely with the purpose of traditional knowledge. The studies of the algae Hypnea musciformis properties enrich and continuously support the vulnerable and local population community, in terms of development of their industry. Besides, this study intends to start evaluating how secure Hypnea musciformis extracts added in cosmetic products are. Moreover, how they are made with well-known commercial compound basis allowed in Colombia.

The purpose of this study is to prove that these cosmetic products do not cause irritation in the human body. Furthermore, to determine the level of resistance of the products in relation to ultraviolet rays. It also intends to measure how amenable and receptive surveyed people find the smell, texture and color of the products, throughout sensory tests. Additionally, this research work aims to determine the quality of the cosmetic products obtained from extracts of red algae Hypnea musciformis. Which is collected in the Colombian Caribbean coast, through microbiological and physical-chemical tests.

\section{Materials and methods}

The following components were used to make the cosmetic products, which are not prohibited by the Official Journal of the European Union. ${ }^{16}$ These are the chemical compounds used in the elaboration of each product: ${ }^{17-19}$

a. Moisturizing cream: The ingredients of the fatty phase were weighed. They are: ethyl alcohol ${ }^{\circledR} 2.5 \%$, stearic acid ${ }^{\circledR} 2.5 \%$, emulgin $\mathrm{B} 2{ }^{\circledR} 0.5 \%$, isopropyl myristate $1 \%$, glycerol monostearate $1 \%$; they were mixed. The ingredients of the aqueous phase were then weighed. They are: methylparaben sodium ${ }^{\circledR} 0.05 \%$, propylene glycol ${ }^{\circledR} 1.5 \%$, triethanolamine ${ }^{\circledast} 1 \%$, water $79.78 \%$, alga extract ${ }^{\circledR} 1.51 \%$, vitamin $\mathrm{A}^{\circledR}$
$0.3 \%$,vitamin $\mathrm{B}^{\circledR} 0.3 \%$, vitamin $\mathrm{D}^{\circledR} 0.3 \%$, Aloe Vera $7.5 \%$, Collagen $0.75 \%$. The plate was heated to $60^{\circ} \mathrm{C}$ to melt the fat phase and simultaneously the aqueous phase was heated to its boiling point. When the fatty phase was melted and the aqueous phase was boiled, the aqueous phase was added to the fatty phase and it was constantly mixed until a homogeneous mixture was obtained. Then, the base of the cream was left to cool.

b. Sunscreen: The ingredients of the fatty phase were weighed. They are: ethyl alcohol ${ }^{\circledR} 1.66 \%$, stearic acid ${ }^{\circledR} 1.66 \%$, emulgin B2 ${ }^{\circledR}$ $0.33 \%$, isopropyl myristate ${ }^{\circledR} 0.66 \%$, glycerol monostearate ${ }^{\circledR} 0.66 \%$; they were mixed.The ingredients of the aqueous phase were then weighed. They are: methyl paraben sodium ${ }^{\circledast} 0.033 \%$, propylene glycol $^{\circledR} 1 \%$, triethanolamine ${ }^{\circledR} 0.66 \%$, water $91.49 \%$, seaweed extract $^{\circledR} 1.51 \%$, titanium dioxide ${ }^{\circledR} 0.31 \%$. The plate was heated to $60^{\circ} \mathrm{C}$ to melt the fatty phase and simultaneously the aqueous phase was heated to its boiling point. When the fatty phase melted and the aqueous phase boiled, the aqueous phase was added to the fatty phase and continuously mixed until a homogeneous mixture was obtained. Then, the base of the sunscreen was left to cool.

c. Gel mask: The ingredients of the aqueous phase were weighed. They are: Carragel MCH $5722^{\circledR} 2.5 \%$, water $84 \%$, seaweed extract $^{\circledR} 2 \%$, vitamin $\mathrm{A}^{\circledR} 0.4 \%$, vitamin $\mathrm{B}^{\circledR} 0.4 \%$, vitamin $\mathrm{D}^{\circledR} 0.4 \%$, Aloe vera $10 \%$, collagen $0.3 \%$. The water is heated to $60^{\circ} \mathrm{C}$, when it starts to boil the other ingredients are added and mixed constantly until a homogeneous mixture is obtained. Then, this mixture is passed to a mold and left to cool.

\section{Obtaining the extract}

The samples of Hypnea musciformis algae were collected from the rocky shoreline of the Simón Bolívar Airport beach, in the city of Santa Marta (coordinates 11: $07^{\prime} \mathrm{N}$ and $74: 14^{\prime} \mathrm{W}$ ) in July 2016. This collection was completed by researchers from the Biotechnology and Bioprospecting group of Jorge Tadeo Lozano University in Bogotá. The taxonomic identification was executed by the marine biologist Ramón Alejandro Plazas. The algae were subjected to manual removal of epiphytes, washing and drying at $45^{\circ} \mathrm{C}$ in a vacuum oven for 48 $\mathrm{h}$, until the constant weight was obtained.The extract was obtained from $25.00 \mathrm{~g}$ of ground algae and with a supercritical fluid in dynamic mode with carbon dioxide and ethanol as cosolvents $(\mathrm{EtOH} / \mathrm{CO} 2)$, the conditions used were $60^{\circ} \mathrm{C} 30 \mathrm{Mp}$ and $8 \%$ ethanol. ${ }^{15}$

The supercritical phase is based on putting any fluid under pressure and temperature above its thermodynamic critical point, which special characteristics are provided. The supercritical fluids (SF) are presented in an intermediate state level between solid and liquid. This makes its physical - chemical features such as diffusivity, constant dielectric, viscosity and density vary in relation to their normal conditions. ${ }^{20}$

The extraction method was selected. Due to the algae have great diversity of compounds which are produced in their secondary metabolism process. So, extraction techniques from algae are required to be more efficient, conservative and selective. The supercritical fluid technique avoids using large quantities of solvent and energy. ${ }^{21}$

From this extract 5 grams were taken to be added to the formulation of each product. The composition of the antioxidant extract total content of polyphenols is $3.786 \pm 0.116 \mathrm{mg}$ GAE $/ \mathrm{g}$ algae and antioxidant activity measured as $\%$ ABTS inhibition $16.10 \% \pm 1.342 .{ }^{15}$

\section{Microbiological control of cosmetics}

The microbiological quality of the cosmetic products constitutes an 
important aspect for public health. The cosmetic products produced by adding natural compounds such as algae extract, are required a major microbiological control in order to be acknowledged by the regulating institutions. In Colombia the regulating institution is INVIMA. The aim of this test was to determine the microbiological quality of the produced formulations, having natural extracts compounds of Hypnea musciformis as basis that are commercially approved.

Preparation of the stock solution: $10 \mathrm{ml}$ of the sample was added in $90 \mathrm{ml}$ of Peptone water $0.1 \%$ with Polysorbate- $204 \%$ and Lecithin $0.5 \%$ or the diluent containing the neutralizing agents of the preservatives (dilution 10-1) was shaken and placed for 10 minutes at $35 \pm 2^{\circ} \mathrm{C} .22$
Test for Staphylococcus aureus and Pseudomonas aeruginosa:10 $\mathrm{ml}$ of the stock solution was taken and $90 \mathrm{ml}$ of TSB was added. It was mixed and incubated at $35^{\circ} \mathrm{C} 2^{\circ} \mathrm{C}$ for 48 hours. The medium was examined to monitor the growth. Given the case was positive, it was replicated in surface with a handle in a petri dish with VogelJohnson-agar and Cetrimide agar media. The plates were covered and incubated at $35^{\circ} \mathrm{C} 2^{\circ} \mathrm{C}$ for 48 hours. ${ }^{22}$

After incubation, unless none of the developed colonies has the characteristics of tables $1 \& 2$, the sample accomplishes the requirements of Staphylococcus aureus and Pseudomonas aeruginosa. If suspicious colonies are detected, a coagulase and oxidase test is performed. ${ }^{17}$

Table I Characteristics of Staphylococcus aureus in selective media ${ }^{17}$

\begin{tabular}{llll}
\hline Selective medium & Vogel - Johnson Agar & Salted Mannitol Agar & Baird-Parker Agar \\
\hline $\begin{array}{l}\text { Morphological } \\
\text { characteristics }\end{array}$ & $\begin{array}{l}\text { Black colonies surrounded by a } \\
\text { yellow halo }\end{array}$ & $\begin{array}{l}\text { Yellow colonies with } \\
\text { yellow halo }\end{array}$ & $\begin{array}{l}\text { Glossy black colonies with light halo from } \\
2 \text { to } 5 \text { mm }\end{array}$ \\
Gram staining & Gram positive cocci in clusters & $\begin{array}{l}\text { Gram positive cocci in } \\
\text { clusters }\end{array}$ & Gram positive cocci in clusters \\
Coagulase test & Positive & Positive & Positive
\end{tabular}

Table 2 Characteristics of Pseudomonas aeruginosa in selective media ${ }^{17}$

\begin{tabular}{llll}
\hline Selective medium & Cetrimide Agar & Agar F for Pseudomonas & P agar for Pseudomonas \\
\hline Morphological characteristics & Generally green colonies & Generally colorless to yellow & Generally greenish \\
Fluorescein Ultraviolet (UV) Light & Green & Yellow & Green \\
Oxidase test & Positive & Positive & Positive \\
Gram staining & Gram negative bacilli & Gram negative bacilli & Gram negative bacilli
\end{tabular}

Coliform bacteria test: $\mathrm{s} 10 \mathrm{ml}$ of the stock solution was taken and added to a tube with $110 \mathrm{ml}$ of CVB at double concentration with a Durham hood, incubated at $35^{\circ} \mathrm{C} 2^{\circ} \mathrm{C}$ for 48 hours. The medium was examined to check the presence or absence of gas within the tube. If gas is present, a sample is taken and replicated in a CVB tube with $10 \mathrm{ml}$ and Durham tube in single concentration at $44^{\circ} \mathrm{C}$ for 48 hours to detect the presence of fecal coliforms. If gas occurs in the Durham tube, an EMB plate is grown at $35^{\circ} \mathrm{C} 2^{\circ} \mathrm{C}$ for 48 hours and suspicious colonies are identified. ${ }^{22}$

After incubation, if none of the developed colonies has characteristics reported by the limits of acceptability of microbiological tests on cosmetic products subjected to microbiological contamination. Based on the official Gazette of the Cartagena agreement Resolution 1482 of July $4,2012 .{ }^{18}$ The sample will accomplish the requirements of Staphylococcus aureus, Pseudomonas aeruginosa and Escherichia coli.

a. Total mesophilic aerobic microorganism count Maximum limit 5 $\mathrm{x} 10^{3} \mathrm{CFU} / \mathrm{g}$ or $\mathrm{ml}$.

b. Absence of Pseudomonas aeruginosa in $1 \mathrm{~g}$ or $\mathrm{ml}$.

c. Absence of Staphylococcus aureus in $1 \mathrm{~g}$ or $\mathrm{ml}$.

d. Absence of Escherichia coli in $1 \mathrm{~g}$ or ml.18

\section{Ultraviolet (UV) radiation spectrum of the sunscreen and titanium dioxide}

The absorption curve vs. wavelength of sunscreen and titanium oxide was determined. A volume of $1.5 \mathrm{ml}$ was used in the cell of the Thermo Scientific equipment model Evolution 300, with a range of $190 \mathrm{~nm}$ to $400 \mathrm{~nm}$ for each of the samples. ${ }^{23}$ Rank: UVA: 320-400 nm.UVB: $290-320$ nm.UVC: $100-290 \mathrm{~nm}^{2}{ }^{24}$

\section{Skin irritation test in human}

The selection process was completed with 10 people (authorized by the Legal Department of Jorge Tadeo Lozano University in Bogotá DC, May 31, 2019). The Ethics committee for experiments in human beings of Jorge Tadeo Lozano University, approved the protocol of the short term study. This study was focused on preliminary studies of irritation. The mentioned study was approved under the protocol of the Mexican official law NOM-039-SSA1-1993.

Each person was informed about the study. Besides, an admission questionnaire was filled out to enter the trial and a consent letter was signed.

Selecting volunteers: The person must be between the 18-65 age range. The person had to be in a good health condition. The person could NOT be pregnant; the person could NOT be taking antihistamines. 
Sample preparation to apply on the patch: the products to be applied were the cream and the sunscreen. They were applied directly to the skin, a sufficient amount of $2 \mathrm{~cm}$ was applied. ${ }^{25}$

Procedure: The patches were applied on the back of the person. Then, a dot was marked on their backside with a permanent marker. The patch remained visible in order to analyze the results. The patches were applied in an ambient temperature $25^{\circ} \mathrm{C}$ for 24 hours. Then, the patch was removed and the person was analyzed for any skin irritation caused by the product. ${ }^{25}$

The patch method requires only a small part of the skin, which has been divided in quadrants. In one of the quadrants, the product has not been used. This part is the aim of the experiment. ${ }^{26,27}$ This test was performed under medical supervision, by MD Rodrigo Castrillón of the Jorge Tadeo Lozano University (Table 3).

Table 3 Criteria for irritability rating ${ }^{25}$

\begin{tabular}{|c|c|}
\hline Criteria & Rating \\
\hline There is no visible reaction on the skin & 0 \\
\hline $\begin{array}{l}\text { Definite light erythema, without rashes or cracks on the skin or absence of erythema with the presence of } \\
\text { dryness }\end{array}$ & $\begin{array}{l}>0 \text { or } \\
\leq 1\end{array}$ \\
\hline Moderate erythema, there may be some papules or deep fissures and moderate or severe erythema & $\begin{array}{l}>1 \text { or } \\
\leq 2\end{array}$ \\
\hline $\begin{array}{l}\text { Severe erythema (bright red color), generalized papules or severe erythema with slight edema (well defined and } \\
\text { elevated edges) may occur }\end{array}$ & $\begin{array}{l}>2 \text { or } \\
\leq 3\end{array}$ \\
\hline Generalized vesicles or moderate or severe erythema or edema that extends beyond the patch area & $\begin{array}{l}>3 \text { or } \\
\leq 4\end{array}$ \\
\hline
\end{tabular}

\section{Physicochemical properties}

\section{Viscosity}

An Ostwald viscometer type 50905 was used to measure the viscosity of the mask, this consists on measuring the material flow time compared to the water flow. The hydrostatic force of the liquid makes it flow through a capillary tube. A BROOKFIELD Brand Viscometer, Model DV-II + Pro with CP40 screw was used for the sunscreen and the moisturizer.

\section{pH}

A METTLER TOLEDO brand $\mathrm{pH}$ meter, reference Seven Easy, was used. The $\mathrm{pH}$ of the sample was measured by putting it into a test tube containing cosmetic sample, the test was repeated twice. The $\mathrm{pH}$ conditions test was completed with its limit, in order to verify that the cosmetic products were made according to the technical specifications of the Mandatory Regulation Sanitary Notification. Based on the official Gazette of the Cartagena agreement Resolution 1482 of July 4, 2012.

$$
\begin{aligned}
& \text { Acid } \mathrm{pH}: \leq 3.0 \\
& \text { Alkaline } \mathrm{pH}: \geq 10.0 .^{28}
\end{aligned}
$$

\section{Organoleptic analysis}

A sensory test was performed on 100 people by asking them if they liked or disliked the color of the moisturizer and sunscreen on a scale of 1 to $7: 1=\mathrm{I}$ extremely dislike them and $7=\mathrm{I}$ extremely like them. ${ }^{29}$

\section{Relative density}

A BRIXCO brand $50 \mathrm{ml}$ pycnometer and a Fisher Scientific brand model XD-800 balance were used. The empty pycnometer was firstly weighed, then the pycnometer was weighed with water, and then the pycnometer was weighed with the sample.

\section{Results}

\section{Microbiological control of cosmetics}

Figures 1, 2, 4 and 5 show that the test results for Staphylococcus aureus and Pseudomonas aeruginosa were negative, since these bacteria were absent in the moisturizing cream and sunscreen products. According tothe Official Gazette of the Cartagena agreement Resolution 1482 of July 4, 2012, these products are acceptable in the absence of bacteria.

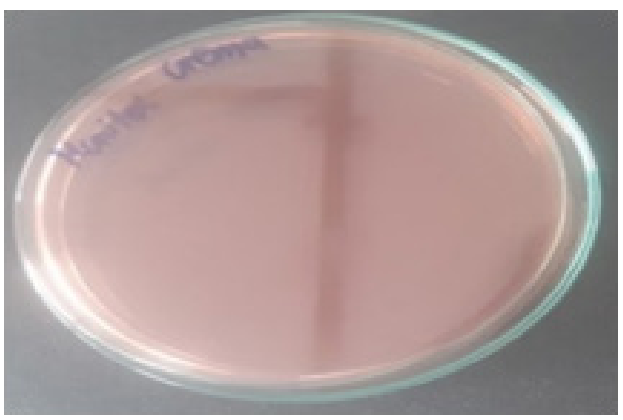

Figure ITest of Staphylococcus aureus in moisturizing cream.

Figures $3 \& 6$ show that the test results for Coliform bacteria were negative. Therefore, these coliform bacteria are absent in the moisturizing cream and sunscreen products. According to the Official Gazette of the Cartagena agreement Resolution 1482 of July 4, 2012. Thelimit of acceptability is satisfactory, since there is no presence. It is to say, there is absence of these bacteria in the products.

\section{Ultraviolet (UV) radiation spectrum of sunscreen and titanium dioxide}

Sunscreen, diluted sunscreen and water with titanium dioxide, the range of these products is measured with the EPA literature. ${ }^{24}$ 


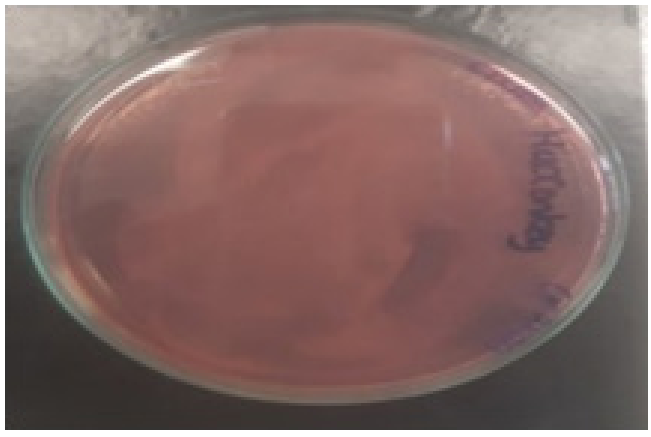

Figure 2 Test of Pseudomonas aeruginosa in moisturizing cream.

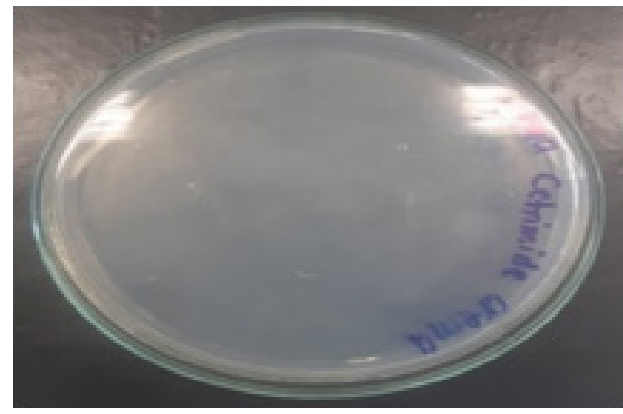

Figure 3 Test for coliform bacteria in moisturizing cream.

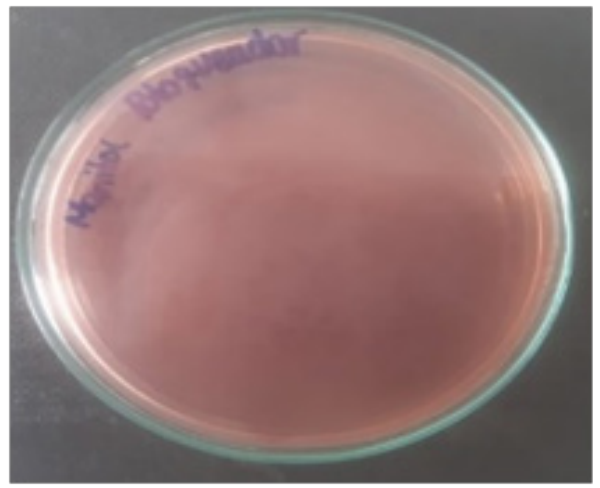

Figure 4 Test of Staphylococcus aureus in sunscreen.

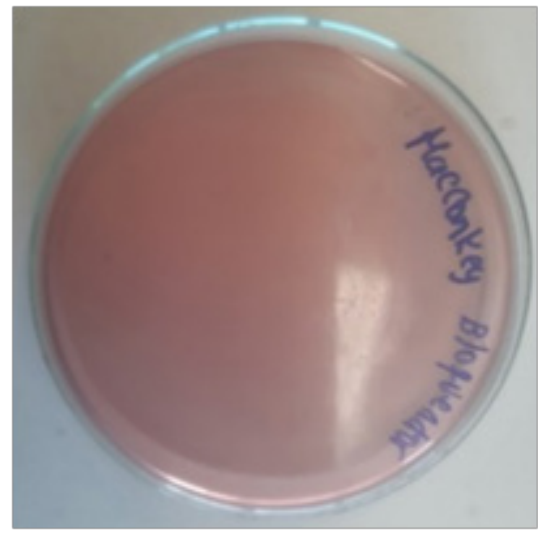

Figure $\mathbf{5}$ Test of Pseudomonas aeruginosa in sunscreen.

Sunscreen: The maximum absorbance of ultraviolet rays at a concentration of $\% \mathrm{w} / \mathrm{v} 0.87$, for UVCs at $190 \mathrm{~nm}$, the maximum absorbance is 3.473 , for UVBs at $290 \mathrm{~nm}$ the maximum absorbance is 2.2 , for UVA at $369 \mathrm{~nm}$ the maximum absorbance is 2.243.Sunscreen was observed to protect from all three ultraviolet rays.

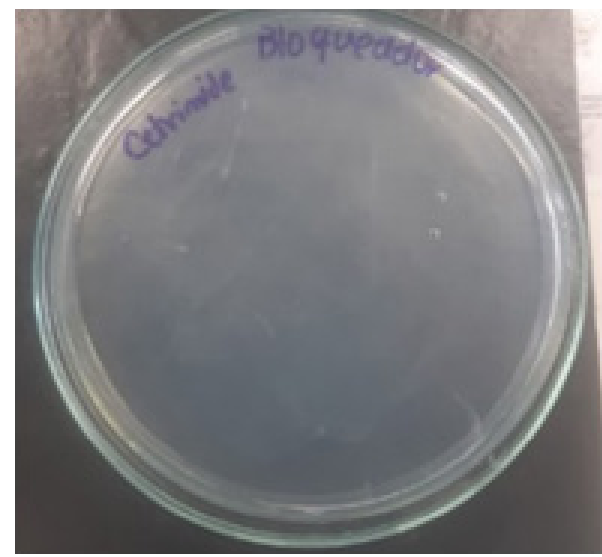

Figure 6 Test for coliform bacteria in sunscreen.

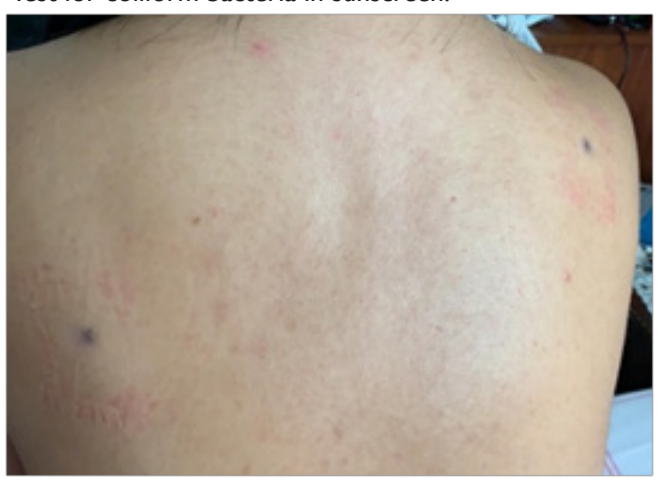

Figure 724 hours after applying the moisturizing cream on the volunteer.

Diluted sunscreen: The maximum absorbance of ultraviolet rays at a concentration of $\% \mathrm{w} / \mathrm{v} 0.035$, for UVCs at $192 \mathrm{~nm}$ the maximum absorbance is 0.379 , for UVB at $290 \mathrm{~nm}$ the maximum absorbance is 0.153 , for UVA at $360 \mathrm{~nm}$ the maximum absorbance is 0.154 .Diluted sunscreen was observed to protect from ultraviolet rays.

Water with titanium dioxide: The maximum absorbance of ultraviolet rays at a concentration of $\% \mathrm{v} / \mathrm{v} 4$, for UVCs at $193 \mathrm{~nm}$ the maximum absorbance is 2.379 , for UVB at $290 \mathrm{~nm}$ the maximum absorbance is 1.296 , for UVA at $320 \mathrm{~nm}$ the maximum absorbance is 1.187.

It was observed that titanium dioxide is able to protect the skin from ultraviolet rays in the different ranges, which are UVA, UVB and UVC. ${ }^{19}$

\section{Human irritation test}

There was no visible reaction on the skin after applying the moisturizing cream and sunscreen products, according to the Criteria for irritability rating (Figure 7, 8). ${ }^{21}$

\section{Viscosity}

Viscosity of the mask: The viscosity of the mask according to the International System (IS) is $7.46 \times 10^{-4} \mathrm{~Pa}^{*}$ s. Figure 9 shows the viscosity of the sunscreen and the moisturizer. Figure 9 shows that these products, i.e., moisturizing cream and sunscreen, have a 
viscosity with a pseudo plastic fluid behavior. The molecules of these products have an orientation parallel to the axis of the surface. ${ }^{30}$

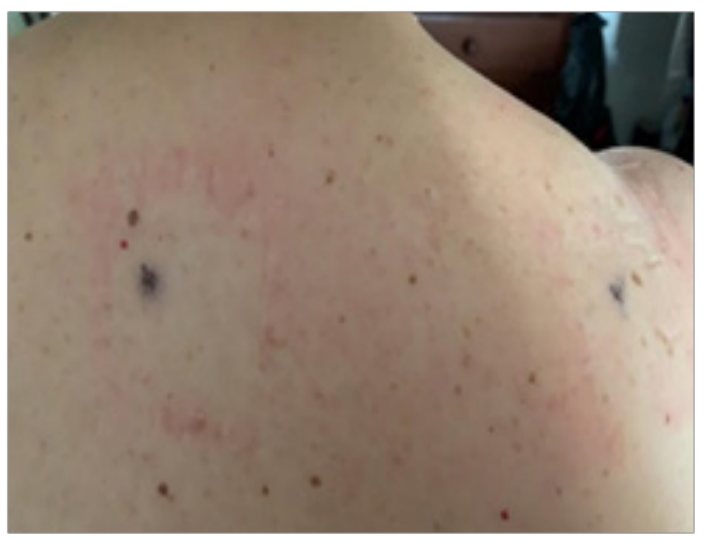

Figure 824 hours after applying sunscreen on the volunteer.

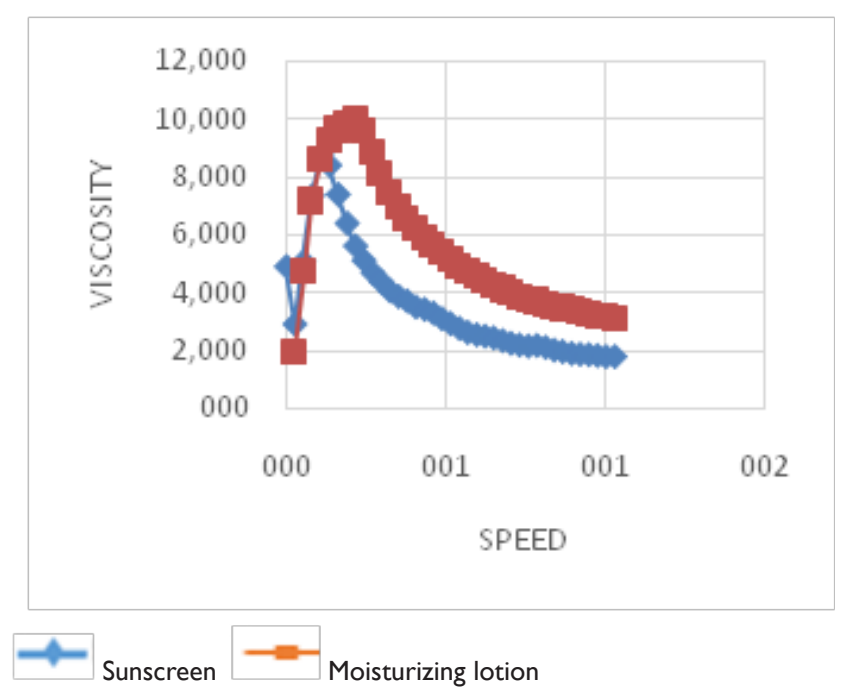

Figure 9 Viscosity result of sunscreen and moisturizer.

\section{pH}

The $\mathrm{pH}$ of cosmetic products was measured and the following results were obtained:

Mask: pH 6.90

Moisturizing cream: $\mathrm{pH} 6.86$

Sunscreen: pH 6.82

The $\mathrm{pH}$ obtained in all products is close to neutrality according to the $\mathrm{pH}$ conditions.Official Gazette of the Cartagena Agreement Resolution 1482 of July 4, 2012. Therefore, it does not have irritating effects on the skin.

\section{Organoleptic analysis}

A statistical study was carried out using the STATGRAPHICS 18 program and a Chi-Square statistic of 75.359 was obtained with a P-value of 0.0000 and with an assurance level of $95 \%$. The results of the 100 surveyed people, showed that the moisturizer in the odor questions averaged 5.42, the texture averaged 5.79, and the color averaged 6.06. In the sunscreen, the odor result had an average of 5.12 , the texture had an average of 5.94 and the color had an average of 5.83. The conducted surveys show an approval in smell, color and texture by the surveyed volunteers.

\section{Relative density}

Each sample was weighed to know its density and the results of the weights were as follows: gel mask: 1.0062 relative density. Moisturizing cream: 0.9337 relative density. Sunscreen: 0.9802 relative density.

\section{Discussion}

Having a body of scientific knowledge for skin health care, the cosmetic products can be produced based on traditional fundamental knowledge. As in this case using Hypnea musciformis in the Caribbean Colombian Coast. However, the phytochemistry studies have allowed isolating some molecules, which are remarkably interesting like the antioxidants. ${ }^{15}$ The fraction, which was taken from the algae extract Hypnea musciformis, is moderately polar. It is present in bioactive compounds, placing algae in a highly important rank for the skin health care and its research development.

In the market there are more than 20 products based on the extract of the macroalgae H. Musciformis, ${ }^{31,32}$ comparing the own created products to the those which are in the market, they do not have the ingredients used in our product. That is to say, our products are more effective. The formulation was created based on the extract of H.Musciformis, vitamin A, B and D, collagen and aloe vera. Although, some cosmetic products have been made with algae extract additives as sunscreens. In general, these have been obtained from microalgae like spirulina. ${ }^{33,34}$

It is essential to determine the bacterial content in cosmetic products. If these products contain microorganisms, it can cause skin health problems and also the damage the product itself. ${ }^{35}$ In the performed test to the products, it showed that there is an absence of bacterial content. Therefore, it is to say, these products will have a durable life and will not cause any health problems on the skin.

The skin irritation test is necessary because it must ensure the products do not cause any skin irritation. In such cases, in which irritation skin may appear, it would be monitored in order to have the percentage of sensitive people as low as possible. ${ }^{27}$ In the product irritation test, a positive result was obtained, since it did not cause any irritation whatsoever to the volunteers.

Physical-chemical tests are performed to detect future problems that may affect the stability and quality of the cosmetic products being made. ${ }^{28}$ Having the obtained results in the $\mathrm{pH}$, viscosity and density test. It was observed that it fulfils with the parameters established in the official Gazette of the Cartagena agreement Resolution 1482 of July 4, 2012. As well as, it demonstrates the quality of the product. Having the approval of products in stability, some aspects must be considered such as the criteria of appearance, color and odor. Plus, the appearance must always remain the same, the color and odor must be stable for more than 15 days. ${ }^{28}$ These products were approved according to the stability criteria. In other words, they meet the requirements in stability and quality test.

The rheological properties found in our formulations, provide the skin important compound products such as collagen and essential vitamins for a healthy skin being protected by the UV light. Although, further and detailed studies are required. The effect of those molecules have been proved in other tests. ${ }^{36,37}$ 
However, in sunscreen lotion is frequently used derived compounds from titanium oxide and Zinc oxide. A product has been developed with similar properties with a more natural formulation with lower concentration of inorganic additives with compounds that are generally soluble in water and higher level of care is needed when applying. ${ }^{38}$

Regarding long term tests, it can be said that sunscreen lotions were originally designed to include filters UVB. Nevertheless, due to an intense increasing penetration of sunlight (UVA), which causes photo-aging. Studies have changed towards sunscreens with UVA and UVB filters, plus other compounds with antioxidant features. ${ }^{39}$

In this sense, it has been started producing sunscreen with broadspectrum using macro algae. And being sunscreens with a broad spectrum, in most countries, photostability tests are not requested. Owing to the complexity of most of these formulations, they can include more than one compound responsible for UV filters, antioxidants, and other excipients of the formulation. ${ }^{39}$

Based on the findings of this study, it has been possible to conclude that the supercritical extract of the alga includes antioxidant agents that work as sunscreen. However, further research and more clinic tests are needed in order to identify the functionality proven in this study. It would be highly important to have an additional test of the presented formulations to determine the efficacy in water solubility, to recommend them as sunscreen to be used for instance in swimming pools or the sea. Because of the selected alga proceeds from a local village surrounding the Colombian Caribbean coast. ${ }^{40,41}$

\section{Conclusion}

H. musciformis extracts could be considered effective ingredients to be used in sunscreen and moisturizer formulations. The combination of vitamins A, B and D, Aloe vera and collagen together with algae extracts significantly improves its properties. The high performance of sunscreens can prevent UV-induced DNA damage. Therefore, they can be considered as an interesting combination for an effective moisturizing and photo protective formulation with anti-aging properties. The $\mathrm{pH}$ obtained in all cases is close to neutrality. Hence, it does not have irritating effects on the skin. The values obtained in the viscosity and density of the products significantly support the texture and the application of cosmetic products. The cutaneous application of all the studied formulations showed significant results statiscally speaking, concerning a moisturized skin. Besides having a positive effect after the treatment with the active compound ingredients from H. musciformis extract, vitamins A, B, D, aloe vera and collagen.

\section{Acknowledgments}

None.

\section{Conflicts of interest}

This research does not have a conflict of interest.

\section{References}

1. Peña Salamanca EJ. Algae as indicators of contamination. Programa Editorial Universidad del Valle; 2005.

2. Schnetter Reinhard, Marie S. Notes on some species of the order Gigartinales (Rhodophyceae) on the Atlantic Coast of Colombia; 1967.
3. Gordon MH. Measuring antioxidant activity. In: Pokorny J, Yanishlieva $\mathrm{N}$, Gordon MH, editors. Antioxidants in food: practical applications. CRC Press; 2001.

4. Radulovich R, Umanzor S, Cabrera R. Tropical Algae Cultivation and Use as Food 2013. San josé de Costa Rica; 2013.

5. Arenas PM, Guayta SL. Algae: cosmetics and health. Museum. 1998; $11: 83-86$

6. Hjerpe LS. U.S. Patent and Trademark Office. Legal Ref Serv $Q$. 2003;22(1):53-65.

7. Bravin IC, Yoneshigue-Valentin Y. Influence of environmental factors on the in vitro growth of Hypnea musciformis (Wulfen) Lamouroux (Rhodophyta). Rev Bras Botânica. 2002;25(4):469-474.

8. Hernández-Barrera NR, Moncada B, Navarrete-Solís J, et al. Evaluation of moisturizing creams available in Mexico. Gaceta médica de México. 2011;147(3):270-274

9. Mena Carrillo CA. Business plan for the production and export of organic cocoa-based face masks to New York City, United States; 2017.

10. IDEAM. Overview of ultraviolet radiation; 2019.

11. Ecuador colombia and peru receive the highest uv radiation throughou the planet; 2019.

12. Team of editors and team of medical editors of the American Cancer Society. What is ultraviolet (UV) radiation?; 2017.

13. Oliveira BPP, Rodrigues F. Plant Extracts in Skin Care Products; 2018. $131 \mathrm{p}$.

14. Radice M, Manfredini S, Ziosi P, et al. Herbal extracts, lichens and biomolecules as natural photo-protection alternatives to synthetic UV filters. A systematic review. Fitoterapia. 2016;114:144-162.

15. Rozo G, Rozo C, Puyana M, et al. Two compounds of the Colombian algae Hypnea musciformis prevent oxidative damage in human low density lipoproteins LDLs. J Funct Foods. 2019;60:103399.

16. Oficial D, Del CE, Europeo P, et al. Diario Oficial de la Unión Europea L 337/11. 2009;2009(9):11-36.

17. Akhtar N, Yazan Y. Formulation and in-vivo evaluation of a cosmetic multiple emulsion containing vitamin $\mathrm{C}$ and wheat protein. Pak $J$ Pharm Sci. 2008;21(1):45-50.

18. Jan P. United States patent. 1943;12(19):2-4

19. Malley ARO, Muller GF. United States patent. Geothermics. 1985;14(4):595-599.

20. Reyes-Najar A, Rangel-Mendoza JA, Nivia-Quintero A, et al. Design and Construction of Extraction Equipment with Supercritical Fluids (Efs) and Some Applications in Food Analysis. 2008;13(13):1-5.

21. Velasco RJ, Villada HS, Carrera JE. Applications of Supercritical Fluids in Agroindustry. Technological information. 2007;18(1):53-65

22. Horak C, Torno G, Zarankin E. Manual of microbiology applied to the pharmaceutical industries, cosmetics and medical products; 2013 23-28 p.

23. Hayden CGJ, Cross SE, Anderson C, et al. Sunscreen Penetration of Human Skin and Related Keratinocyte Toxicity after Topical Application. Skin Pharmacol Physiol. 2005;18(4):170-174.

24. UV Radiation. EPA; 2010

25. Moctezuma J. Official Mexican standard nom-039-ssa1-1993, goods and services. Perfumery and beauty products. Determination of eye irritation, primary dermal and sensitization indices; $1993.1-34 \mathrm{p}$. 
26. Wetter DA, Yiannias JA, Prakash AV, et al. Results of patch testing to personal care product allergens in a standard series and a supplemental cosmetic series: An analysis of 945 patients from the Mayo Clinic Contact Dermatitis Group, 2000-2007. J Am Acad Dermatol. 2010;63(5):789-798.

27. Li B, Zou Y, Cheng Y, Hu W, et al. 348 Prevalence of skin allergy and irritation to cosmetics and associated factors in China: Lessons from more than 600,000 patch test case reactions from over 10,000 individual visits. J Invest Dermatol. 2018;138(5):S59.

28. Comunidad Andina. RESOLUTION 1482 - Modification of Resolution 1418: Limits of microbiological content of cosmetic products; 2012.

29. Ramírez-Navas JS. Sensory analysis: consumer-focused tests; 2019.

30. Brookfield Engineering Labs. Brookfield Dial Viscometer: Operating Instructions. Manual No. M/85-150-P700; 2013. 34 p.

31. SpecialChem. Hypnea musciformis extract Cosmetic Ingredient (INCI); 2020 .

32. EWG Skin Deep®. What is Hypnea Musciformis (HYPNEACEAE) extract; 2020

33. Souza C, Campos PMBGM. Development and photoprotective effect of a sunscreen containing the antioxidants Spirulina and dimethylmethoxy chromanol on sun-induced skin damage. Eur J Pharm Sci. 2017;104:52_64.
34. Ariede MB, Candido TM, Jacome ALM, e al. Cosmetic attributes of algae-A review. Algal Res. 2017;25:483-487.

35. Herrera E. Irritability and sensitivity tests in cosmetics. Farmazine; 2019.

36. Marinelli L, Cacciatore I, Eusepi P, et al. Viscoelastic behaviour of hyaluronic acid formulations containing carvacrol prodrugs with antibacterial properties. Int J Pharm. 2020;582:119306.

37. Mãdãlina Georgiana ALBU, Minodora LECA VT. Rheological behavior of some collagen creams. Revista de Pielarie Incaltaminte. 2012;12(4):257-271.

38. Jeon S kyung, Kim E ju, Lee J, et al. Potential risks of $\mathrm{TiO} 2$ and $\mathrm{ZnO}$ nanoparticles released from sunscreens into outdoor swimming pools. $J$ Hazard Mater. 2016;317:312-318.

39. Kockler J, Oelgemöller M, Robertson S, et al. Photostability of sunscreens. J Photochem Photobiol C Photochem Rev. 2012;13(1):91110 .

40. Santos AJM, Miranda MS, Esteves da Silva JCG. The degradation products of UV filters in aqueous and chlorinated aqueous solutions. Water Research. 2012;46(10):3167-3176.

41. Wang SQ, Lim HW. Current status of the sunscreen regulation in the United States: 2011 Food and Drug Administration's final rule on labeling and effectiveness testing. Journal of the American Academy of Dermatology. 2011;65(4):863-869. 